\title{
A branca sintaxe na poética de Haroldo de Campos
}

Rodrigo Guimarães I Universidade Estadual de Montes Claros

Resumo: Este ensaio busca rastrear a poesia de Haroldo de Campos a partir do conceito de sintaxe branca, com o propósito de elucidar alguns procedimentos operados na materialidade da linguagem. Para tanto, foram analisados, especialmente, os livros Galáxias eCrisantempo. Palavras-chave: Haroldo de Campos, Poesia Contemporânea, Desconstrução.

\author{
Na poesia de Haroldo, o espaço \\ se ergue à altura das palauras \\ Donaldo Schüler
}

Crítica e inovação: dois vocábulos que obsedaram Haroldo de Campos e que, tomados na espessura de seu pensamento, representam com precisão uma atividade textual que se estendeu por mais de cinqüenta anos, construindo, de modo ininterrupto, uma fortuna crítica que ainda resta por ser determinada.

Os livros de Haroldo de Campos aqui selecionados (Galáxias e Crisantempo) pertencem a sua fase "pós-utópica", uma vertente menos conhecida de sua poesia que se inicia nos meados dos anos 60, momento em 
que o movimento da poesia concreta começa a se exaurir enquanto ação coletiva e experimento em progresso. No entanto, o concretismo deixou traços fundamentais que permaneceram até os dias atuais: não a utopia nem a ditadura estética vanguardista, mas a consciência crítica que recusa o sentimentalismo em prol de uma concepção que leva em consideração as operações materiais com a linguagem, bem como seu modo de criar e pluralizar sentidos a partir da organização formal do texto.

Como se sabe, Décio Pignatari, Augusto e Haroldo de Campos se posicionaram decididamente contra as tendências "sensorialistas" da poesia moderna, defenderam a "construção" em detrimento da espontaneidade e do subjetivismo, fizeram a crítica do pensamento retórico-discursivo e, em seu momento inicial, conhecido como a fase ortodoxa do grupo, estabeleceram uma plataforma de ação e seus campos de inovação: semântico (polissemia, trocadilho, contra-senso); sintático (atomização do discurso, justaposição); léxico (neologismos, substantivos concretos, palavras estrangeiras, tecnicismo); morfológico (desintegração do sintagma em seus morfemas, separação dos prefixos, dos radicais e dos sufixos); fonético (aliterações, assonâncias, paronomásias, rimas internas); topográfico (abolição do verso, não-linearidade, uso construtivo dos espaços brancos, ausência de sinais de pontuação).

Cumpre destacar, na fase concretista de Haroldo de Campos, não só suas reflexões antinormativas em relação à tradição verocêntrica, mas, sobretudo, alguns procedimentos recorrentes na construção de sua poética, que dizem respeito à disposição da matéria gráfica e a algumas concepções de uma sintaxe desestabilizadora, com elementos de indeterminação. ${ }^{1}$

Julgo imprescindível sublinhar essas operações desconstrutoras (concentração sígnica, saturação da matéria verbal e esvaziamento referencial) já presentes em seus primeiros poemas concretos, pelo fato de elas o terem acompanhado em toda sua trajetória textual. Haroldo de Campos reconhece, em entrevista concedida à Revista Cult, que, embora tenha se desvencilhado da poesia concreta desde meados da década de 1960, sempre continuou a trabalhar com a materialidade da linguagem numa grande variedade de diç̧ões. Ao se referir a Galáxias (obra ápice que se distancia do concretismo no

1. Esses elementos de indeterminação recebem uma elaboração mais precisa nos textos de Jacques Derrida. denominados por ele de indecidíveis. 
sentido da proliferação dos signos), ele acentua os elementos de concreção presentes na microestrutura do poema. ${ }^{2}$

Ao encerrar a sua experimentação programática com o concretismo, Haroldo iniciou uma fase que denominou de pós-utópica, possível de ser observada com a publicação dos primeiros fragmentos de Galáxias, em 1964 (poema escrito entre 1963 e 1976). Essa escritura consiste numa pluralização das poéticas possíveis, não sendo, portanto, nem pósmoderna nem antimoderna, mas "pós-vanguarda", em que o princípioesperança é substituído pelo princípio-realidade, como elucida o próprio poeta em sua obra $O$ arco-íris branco. ${ }^{3}$

Essa poesia da "agoridade", segundo Haroldo, evidencia-se por meio de sínteses provisórias em que há uma apropriação crítica da tradição ao mesmo tempo em que coloca em xeque uma concepção do futuro e de seus "paraísos sistemáticos".

Pode-se situar o poema Galáxias como uma marca distintiva na vasta obra poética de Haroldo de Campos, evidenciando o início de uma flexibilização progressiva em relação ao concretismo, em que o poeta se afasta dos conteúdos programáticos da vanguarda e constrói um poema longo, com uma linguagem híbrida (mistura de prosa e poesia), permitindo a presença de um "eu lírico" (não confessional) numa escritura que comporta alguma discursividade e momentos epifânicos. É o próprio poeta quem reconhece em Galáxias o início de um novo rumo em sua produção, em função de um distanciamento dos anos "ortodoxos". Nesse poema há uma multiplicidade de vozes e linguagens que se entrelaçam em um tecido complexo constituído

2. Cf. Revista Cult, n. 13, p. 20.

3. Cf. o ensaio "Poesía e modernidade: da morte da arte à constelação. O poema pós-utópicó” em O arco-íris branco, 1977.

4. Para Haroldo de Campos, a poesia pós-utópica "não necessita mais, para denifirse, de recorrer a uma oposição dominante, seja a um dado passado, seja a si mesma”, preceitos caros à modernidade. Entretanto, o poeta não pode abrir mão do resíduo utópico constituído pela dimensão crítica que caracterizou a modernidade. A tradução, para os poetas modernos, instaura-se como mais um dispositivo crítico de presentificação de uma pluralidade de "passados", que são recombinados (por um processo reflexivo e criativo) no ato da tradução. Cf. CAMPOS, O arco-íris branco, p. 269 
de expressões orais, slogans políticos, frase de pára-choque de caminhão, diálogos coloquiais entrecortados por reflexões sobre a linguagem, bem como elipses, atravessamentos de palawas ou frases em língua estrangeira, dentre outros artifícios que pulverizam uma narratividade linear e as referências fixas de sujeito ou de mundo.

A análise em maior profundidade efetuada por Haroldo de Campos sobre a poesia da presentidade, acredito eu, encontra-se em seu ensaio "Poesia e modernidade: da morte da arte à constelação. O poema pósutópico". Nesse artigo, o poeta declara que o momento atual não é pósmoderno, mas pós-utópico. O princípio-esperança era a crença em um futuro que seria "a realização adiada do presente, que anima a suposição que, no limite, a poesia universal progressiva possa ocupar o lugar socializado do jornal". 5 Outros horizontes utópicos também permearam as formulações concretistas, tais como mastigar e refazer o código da poesia do Oriente e do Ocidente em uma linguagem ecumênica em que o legado da poesia universal é repensado e usurpado (sob a bandeira descentrada da razão antropofágica).

É esse princípio-esperança que mobiliza o trabalho em equipe e a renúncia às particularidades, favorecendo um resultado que responda aos programas coletivos e que, concomitantemente, apague as diferenças ao alienar a singularidade. Posteriormente, ainda seguindo a análise de Haroldo, em um "ponto de otimização da história", os sujeitos se desalienam por um processo desdiferenciador e progressivo.

A poesia pós-utópica (da presentidde), assim como formulada por Haroldo de Campos, substituiu o princípio-esperança (e sua visada utópica) pelo princípio-realidade, visto como pluralização das poéticas possíveis sob a perspectiva de uma história plural. Há, portanto, na poética da agoridade uma crítica do futuro e de seu mapeamento idílico ou monológico, bem como do passado e de suas interpretações hermenêuticas ou finalistas que paralisam a semiose infinita dos entrechoques sígnicos. O presente torna-se, então, o lugar onde se operam confluências e dissonâncias capazes de capitanear diferentes regimes de circulação de significantes e reelaborar, incessantemente, sínteses na profusão babélica de linguagens advindas das

5. Cf. O arco-iris branco, p. 265. 
mais variadas culturas e momentos históricos. Daí a importância de preservar o que Haroldo de Campos chamou de resíduo utópico presente no componente crítico que caracterizou a modernidade, a fim de evitar um laissez faire que sirva "de álibi ao ecletismo regressivo ou à facilidade". Essa apropriação "dos passados" (que não necessita mais do procedimento moderno da negação e do cancelamento dos códigos recentes) dá-se pelo viés ensaístico ou por outras formas textuais que sao suplementadas pelo dispositivo crítico da operação tradutória, visto por Haroldo como "prática de leitura reflexiva da tradução - permite recombinar a pluralidade dos passados possíveis e presentificá-la, como diferença, na unidade (aqui e imediatamente) do poema pós- utópico". ${ }^{6}$

Diante do exposto, evoco, ainda que brevemente, alguns dos procedimentos recorrentes na poesia haroldiana que leva em consideração não só o uso do espaço como elemento de sintaxe, mas a reflexão no próprio corpo do poema sobre os brancos e espaçamentos (Derrida) que entremeiam a escrita poética, operação que denominei de "sintaxe branca".

\section{A sintaxe branca}

O uso do espaço como elemento de composição sempre fascinou Haroldo de Campos tanto na fase do concretismo, exemplificado pelo seu poema "o âmago do ômega" em que o poeta eleva "zero ao zênit" e o espacializa na página, quanto em outros poemas recentes de Crisantempo (1998). Esse é o caso de "nékuia: fogoazul em Cubatão". Poema que perfaz sete páginas e comporta uma referencialidade explícita quando expõe sua dimensão "documental-ecológica". No entanto, evidenciam-se os processos de concreção da linguagem com o propósito de fragmentar o "azul", as "azas", o "azar", e de colocar o "ar" em suspenso, entre parênteses, deixando um uivo (UL) como resíduo do azul e do poema. Lido ao revés, sugerindo uma inversão dos vetores de destruição sócioambiental, o uivo torna-se LUz.

6. Cf. O arco-íris branco, p. 269. 
O eixo e a roda: $v .13,2006$

Disponivel em: http://www.letras.ufmg.br/poslit

\section{o polegar baixando}

d a n a çã o

últimos lêmures

o êxito ao revés

UL

/sem az (as)

(ar)

de $\quad$ az

UL

No entanto, em Galáxias e Crisantempo existem formulações poemáticas que dialogam de maneira direta com a sintaxe branca e suas operações metonímicas ou de espaçamento. Vejamos, em Crisantempo, algumas abordagens dessa temática: "a poesia pensada como um ponto cego na retina"; "zeros e ratos - fatos" (poema qohelético 1); "o canto zero das térmitas" (poema qohelético 2); "ZENbranças sem ponto focal" (merce cunningham).

Note-se que o branco (o ponto cego, o zero) não é caracterizado por uma negatividade de tipo dialético, e sim como operador textual que atua desconstruindo, corroendo, tais como os ratos e os cupins. Ou, por um outro viés, agem por um processo de esvaziamento (zen) das lembranças com feição subjetivísta, promovendo um despojamento da maneira reticulada em que se desenha a realidade.

Em Crisantempo, a negação adquire matizes variados. Às vezes assemelha-se ao nem/nem derridiano, não sendo afiançada por nenhum sistema oposicional, como se vê no poema "refrão à maneira de brecht", em que a instância elocutória anuncia: "contra o bloqueio de cuba mas também contra a contumácia 'dinosssáurea'de - mário soares dixit - Fidel [...] contra os ensandecidos xiitas palestinos mas também contra a surdez míope dos judeus fundamentalistas". Em outros momentos, tais como no poema "rima petrosa 2", a partícula de negação (o "não") instaura um movimento bem mais difícil de ser apreendido. Após iniciar o poema com uma negação absoluta ("não da planta do pé à palma da mão"), o poeta cria um movimento de rimas, ecos, elipses e paradoxos, que impossibilita a caução dos significados em um jogo de simplicidade dual: "mas se de tamanho não/ tão unânime um não

tão/ se dessa massa de nãos/ como da massa de pão/ fermentar um dia um 
sim [...] serei eu a/ dizer não/ um não de sins/ o meu não [...] coração que bate sim/ encarniçado em seu não".

Ressalte-se, no poema referido, o processo desconstrutor que põe em causa o próprio sistema opositivo da negação dialética que se dá por meio de uma "acumulação com tensão". Em vez de deslocar os códigos mediante o processo de metaironia, assim como fez Octavio Paz em seu poema "Blanco" ("não e sim/ juntos/ duas sílabas enamoradas"), Haroldo de Campos segue a tradição da "razão antropofágica" ao lidar com a matéria indócil que sempre constitui rasuras e relhas sobre a indolência vocabular.

Todavia, existem também, em Crisantempo, desconstruções que se inclinam em direção aos paradoxos zen, causando injunções na lógica ocidental. É o que acontece na tradução do texto do zenrinkushu, espacializada sobre a página na forma de duas linhas paralelas e verticais: "a onda revela a essência da lua"; "a árvore desvela a substância do vento".

\section{A sintaxe branca em Galáxias}

Torna-se evidente, após alguns passos no solo infirme de Caláxias, a impossibilidade de uma leitura sem desapossá-lo ou recorrer aos processos de espoliação de seu fluxo textual. No livro-viagem, de cinqüenta páginas, em que não existe nenhuma pontuação, o leitor é convocado a inventar uma forma de respirar, estipular os pontos de basta (Lacan) para atar o sentido e identificar os valores de legibilidade. Essas operações são realizadas apenas de forma parcial. Mesmo diante de uma leitura em filigrana, não há como reintroduzir o texto galáctico num registro inteiramente conhecido, a não ser pelo engessamento segmentar decorrente das cifragens categoriais.

7. Em Galáxias, no fragmento 15 (musicado em parte por Caetano Veloso em seu CD Circuladô de fulô), vê-se uma construção bem mais minuciosa das sobreposições das partículas de negação e de positivação, em que o "não" se desloca do lugar de oposição externa e se insere no corpo anteriormente negado, instaurando uma tensão intrínseca ao próprio objeto: "e não fie desafie e não confie desfie que pelo sim pelo não para mim prefiro o não no senão do sim ponha o não no im de mim ponha o não o não será tua demão..."

Em Galáxias (o livro-viagem, na expressão de Haroldo), não há numeração das unidades-páginas. Para facilitar o processo de citação, vou referi-las como fragmentos (o frag. 1 corresponde a primeira página, e assim sucessivamente). 
Em Galáxias, quase tudo o que se passa, passa-se na linguagem. Em outra formulação, pode-se dizer que ocorre uma espécie de conversão do nome no objeto, da palavra na coisa, da designação na expressão. A respeito desse movimento que denota um desvanecimento da separação entre linguagem e objeto, João Alexandre Barbosa, em seu ensaio "Haroldo de Campos: um Cosmonauta do Significante", identifica um processo de desalienação radical, embora, é preciso acrescentar, no livro-viagem, a volatização das referências nunca erija o esvaziamento pleno da significação.

Mas mesmo esse mínimo de referencialidade, que se dá por meio das micronarrativas ou plurinarrativas, é extremamente desestabilizado. É freqüente no livro-viagem as cadeias significantes serem entrecortadas por outras ou as séries sígnicas saturarem o mesmo espaço semântico, assim como acontece com os fragmentos das conversas cotidianas que se entrechocam na multidão: "Jogo com técnicas de narrativa que fraturam, transgridem, tornam ambíguos o espaço e o tempo épico, os caracteres. Altero os registros retóricos. Dissemino as citações que dão uma entonação multíplice às 'falas' e confundem as vozes narrativas".

A sintaxe branca, em Galáxias, se refere a um feixe complexo de ressonâncias de significantes: a cal, o vazio, a lacuna, o entre-espaço, o nada. Esse branco, como todo indecidivel (no sentido que lhe confere Jacques Derrida), não preexiste às cadeias significantes, mas compõe com elas uma intrincada rede de significância que varia imensamente de uma operação a outra. Sem o recurso "material" do espaço, assim como se vê nos poemas concretos, Haroldo de Campos inventou outras formas para evocá-lo mediante construções sígnicas que possibilitam intensa visualidade ou sutis abstrações "teorizantes" vincadas na relojoaria rítmica.

O palimpsesto do fluxo galáctico, por assim dizer, convoca o leitor a rasurá-lo mediante "outro escrito de outro branco" e, no mesmo golpe, cometer o incesto, deixar um resto branco no papel de "pele de seda". Esse resto branco é a impossível operação em que "escrever sobre o escrever

8. Cf. Do Epos ao Epífàníco (Gênese e Elaboração das Galáxias), p. 275. Para Haroldo de Campos, a incorporação, no texto poético, de elementos da linguagem prosaica e conversacional tanto no campo lexical quanto na esfera sintática contribuíram de forma fundamental para a dissolução da pureza dos gêneros. Ver Ruptura dos gêneros na literatuta Latino-americana, p. 14. 
é não escrever sobre o não escrever" (Galáxias, fragmento I). Escrever sobre o não escrever foi feito por Artaud, que se esforçava de forma extrema para dizer que não podia escrever. Mas esse "duplo não" haroldiano é outra coisa (não se refere à dupla negativa que se converte em afirmação). Essa "outra coisa" "faz-se ranhura entre nada e nada".

Isso, talvez, é o não escrever sobre o não escrever, o Real que se mostra (Wittgenstein) na relação escritura-mundo. No entanto, há o movimento incessante do pulsional rumo à apropriação das margens (que pode consumarse ou não) e que se realiza ora no espaço amoedado pelo significado, ora na significância que se apropria do espaço.

Vez por outra, em Galáxias, o branco é o calado do branco não tocado "que as letras dactilonegam negram sonegam". Percebe-se uma mudança de direção em que o branco deixa de ser produtivo e aparece associado à imagem do recalcado psicanalítico: "a córnea branca do nada que é o tudo estagnado". A essa estagnação desfilam-se, em muitos fragmentos do livroviagem, imagens de rebaixamento do significante branco: "o papel-carcaça fede-branco osso que supura esse esqueleto verminoso". Entretanto, assim como o inconsciente e seus brancos contidos pelas diversas maquinarias sociais e da linguagem, existem momentos em que o branco do fluxo galáctico eclode: "mola de brancura nos jogando branquíssima elástico de candura nos alvíssimo atirando contra o horizonte rojonegro" (Fragmento 2).

Se em certas passagens Haroldo de Campos parece se aproximar de algumas concepções psicanalíticas, como no fragmemo 2 ou 35 ("o branco é uma linguagem que se estrutura como a linguagem"), em outras, a mudança de direção é absoluta: "passar da palavra garça à palavra albina é uma veloz operação de brancura que não deixa na página mais do que esta marca de água" (fragmento 40). ${ }^{9}$

9. É pertinente a observação de Donaldo Schüler quando diz: "o branco, tendo tomado o lugar do inconsciente lacaniano, não pode ser posto na categoria de estruturas fixas". Cf. Um lance de nadas na épica de Haroldo. Disponível em http://www.schulers.com/donaldo/haroldo/har9.htm. No entanto, penso ser necessário, no que diz respeito às operações de brancura no livro-viagem, ir além da concepção de "estrutura", mesmo que esta seja reduzida a um mínimo. Os conceitos de rastro, espaçamento e différance, assim como elaborado por Jacques Derrida, bem como a dobra deleuziana se acoplam melhor à maioria das operações sígnicas do fluxo galáctico. 
Considerando a formulação de Jacques Derrida sobre o espaçamento, pode-se sugerir, com Haroldo de Campos, que essa marca d'água é "o espaço entre do entre-espaço onde o vazio inscreve sua insígnia todos os possíveis permutam-se nesse espaço de antimatéria que rodeia a matéria de talvez" (fragmento 35).

As operações de espaçamento possibilitam a palavra poética transpassar uma "visão de mundo" (mesmo pluralística) e se furtar à apreensão conceitual e de sentido. O fluxo galáctico é pródigo em fragmentos insurrectos que operam uma transgressão das leis da lógica aristotélica. Em alguns momentos de Galáxias, toda a ênfase é colocada no instante de fruição ou de cintilação entre as margens da escritura (o que possibilita a circunscrição do sentido) e a perda-gozo se dá no espaço-interstício: "um livro é o vazio do livro a viagem é o vazio da viagem [...1 o vazio do vôo o vôo do vôo" (fragmento 21).

A "fome de forma" haroldiana, já presente em sua fase concreta, promove em Galáxias uma diferencialidade muito mais complexa de espaçamentos e marcas d'água que não se deixam monadologizar. Levantar as âncoras que sustentam o leitor instalado confortavelmente em seu topos é um dos efeitos dessas operações de brancura, promovendo o ressituar contínuo das alavancas que deslocam as cadeias de significantes ao mesmo tempo em que potencializam e desestabilizam os códigos da língua.

São esses processos menos permeáveis à significação e que abrem flancos nas camadas sedimentarizadoras que são priorizadas na branca sintaxe de Haroldo de Campos.

Abstract: This essay focuses on the poetry of Haroldo de Campos, in the light of the concept of white sintaxe. It aims to show how the poet works with the material and spacial aspect o language on bis books Galaxias and Crisantempo. These issues are emphasized, especially, by the creative and critical reinvention that the authors make of tradition, as well as by the utilization of deconstruction resources in his writing.

Key words: Haroldo de Campos, Contemporary poetry, Deconstruction. 
Belo Horizonte, p. 1-232

Disponível em: bttp://www.letras.ufmg.br/poslit

Referências Bibliográficas

AGUILAR, Gonzala. Poesia concreta brasileña: las vanguardias en la encrucijada modernista. 2003. Tese (Doutorado em Letras) - Universidade de Buenos Aires, Buenos Aires, 2003.

BARBOSA, João Alexandre. As ilusões da modernidade. São Paulo: Perspectiva, 1996.

CAMPOS, Haroldo de. O arco-iris branco. Rio de Janeiro: Imago, 1977.

CAMPOS, Haroldo de. Metalinguagem e outras metas. São Paulo: Perspectiva, 1993.

CAMPOS, Haroldo de. Galáxias. São Paulo: Ex-Libris, 1984.

CAMPOS, Haroldo de. Crisantempo. São Paulo: Perspectiva, 1998.

CAMPOS, Haroldo de. A arte no borizonte do provável. São Paulo: Perspectiva, 1969.

CAMPOS, Haroldo de. Dois dedos de prosa sobre uma nova prosa. Invenção: Revista de arte da vanguarda, São Paulo: Edições Invenção, n. 4, dez. 1964.

CAMPOS, Augusto; PIGNATARI, Décio; CAMPOS, Haroldo. Teoria da Poesia Concreta: textos críticos e manifestos, 1950-1960. São Paulo: Livraria Duas Cidades, 1975.

DELEUZE, Gilles. A dobra. Leibniz e o barroco. Trad. Luiz Orlandi. São Paulo: Papirus, 1991.

DERRIDA, Jacques. Gramatologia.2. ed. Trad. Miriam Chnaiderman. São Paulo: Perspectiva, 1997.

DERRIDA, Jacques. La desconstrucción em lãs fronteras de la filosofia: la retirada de la metáfora. Trad. Patrício Peñalver Gómez. Barcelona: Paidós Ibérica, 1996.

DERRIDA, Jacques. Margens: da filosofia. Trad. Joaquim Torres Costa e Antônio Magalhães. Campinas: Papirus, 1991.

LACAN, Jacques. Escritos. Trad. Vera Ribeiro. Rio de Janeiro: Zahar, 1998.

MACIEL, Maria Esther. Pontos de confluência: América Latina em diálogo com o oriente conversa com Haroldo de Campos. In: SANTOS, Luis Alberto Brandão; PEREIRA, Maria Antonieta (Org.). Trocas culturais na América Latina. Belo Horizonte, PósLit/FALE/UFMG, 2000.

MENEZES, Philadelpho. A crise do passado: modernidade. Vanguarda. Metamodernidade.

São Paulo: Experimento, 1994.

NASCIMENTO, Evando. Derrida e a literatura: "notas" de literatura e filosofia nos textos de desconstrução. Niterói: Editora da UFF, 1999.

NASCIMENTO, Evando. Jacques Derrida: pensar a desconstrução. São Paulo: Estação Liberdade, 2005.

PAZ, Octavio. Blanco. México: Seix Barral, 1979.

SILVA, Rodrigo Guimarães. Altino Caixeta e Haroldo de Campos: poéticas da desconstrução. 2006. Tese (Doutorado em Letras) - Universidade Federal de Minas Gerais, 2006.

WITTGENSTEIN, Ludwig. Tractatus logico-philosophicus. São Paulo: Editora Universidade de São Paulo, 2001 